\title{
The Origin and Artistic Characteristics of Chinese Traditional Paper-Cut Art
}

\author{
Yan Guan ${ }^{1}$ Meng Pan ${ }^{1, *}$
}

\author{
${ }^{1}$ School of Art and Design, Wuhan Textile University, Wuhan, Hubei 430073, China \\ *Corresponding author.Email: 851169957@qq.com
}

\begin{abstract}
In the era of cultural globalization, countries around the world have begun to pursue the revival of traditional culture. Paper-cut, as a popular and artistic form of traditional culture in China, has been passed on for many years and is very popular. By studying the cultural origin of paper-cut art and its artistic characteristics, this paper tries to arrange the folk embodiment of paper-cut art and its value connotation, so as to provide more systematic local cultural and artistic resources for contemporary Chinese artists.
\end{abstract}

Keywords: paper-cut patterns, revival of tradition

\section{INTRODUCTION}

The development of economic and cultural globalization requires Chinese artists to make full use of local cultural and artistic resources. Most of their works tend to introduce regional particularity literati paintings, philosophical concepts, Folk Arts, traditional festivals, traditional architecture and other oriental elements with Chinese characteristics to the world. The author hopes to mold the unique style of Chinese art works and promote the fusion and development of folk culture and Contemporary Art. This is also the current paper-cut art development trend. As a representative of the Oriental Arts and styles, paper cutting undoubtedly has deep cultural charm, however, we can not only protect it by placing it on the intangible cultural heritage list, it is also necessary to have a deep understanding of its cultural origin, development and artistic characteristics, so as to have a more comprehensive understanding of the art of paper-cut, so that it can continue to show its unique beauty to the world.

\section{ChaRACTERISTICS OF PAPER CUTTING} ART

\section{A. The unity of practicality and adornment}

As a classic product of Folk Culture, paper-cut art is accompanied with the three most important rites of birth, marriage and funeral in people's life, from the very beginning, it contains the high unity of practicality of life and art of decoration. In decorative, paper cut is often used in wedding customs and festival's posters, so that ordinary people do not spend a lot of time and money to create a festive atmosphere, express sincere wishes. In the traditional wedding custom, in addition to the most classic double-happiness paper-cut, the "new" wishes for the future life of the couple are expressed, all the daily necessities in the wedding room must be newly acquired. To prove that they have never been used, a small piece of paper-cut with the theme of giving birth to children and praying for peace between husband and wife is affixed to each item. In the traditional funeral ceremony, there are paper-cut to do the banners, funeral streamers, to create a solemn atmosphere. At the same time, paper-cut is also used in fan surface and lantern decoration. Gong Luyan's notes on the grass heart tower in the Ming Dynasty recorded that people took the paper-cut from the gifts they received and pasted them on the windows as window decorations. This proves the decorative function of paper-cut at that time and people's love for it.

Paper-cut is very cheap and easy to obtain, art technique is not difficult, the effect is brilliant, very popular with the general public, Folk paper-cut artists are therefore very many. In practical terms, paper cutting can be used as a pattern for embroidery, as a paper draft for engraving work, as a tool for decorating ceramics, and so on, as evidenced by archaeological work as early as nine hundred and sixty ad, jizhou kilns in Jiangxi Province, have mastered the technique of decorating ceramics with paper-cut leakages, making decals more convenient and firing more successful. And now preserved complete vamp pattern, insole pattern, safety lock pattern, belly pocket pattern and so on are also a perfect proof of the practical function of papercutting. Due to the long-term influence of Buddhism and Taoism culture and sorcery culture, paper-cut is also used in the activities of offering sacrifices and evocation. At the same time, with the continuous improvement and development of the imperial 
examination system, the idea of heaven and man as one, and other feudal ideology and moral thought took root in the hearts of the people, the educational function of the paper-cut art also emerged, and its patterns began to have educational significance, they often tell stories of virtue, praise filial piety and etiquette, express the pursuit of life culture, eulogize the desire of good life, and gradually become the classic representatives of the art of social life.

\section{B. Ideological connotation of agricultural civilization}

The agricultural civilization of the slash-and-burn has lasted for thousands of years from the primitive society in China, creating the basic living environment and cultural foundation for the vast majority of the Chinese people, due to the lack of natural scientific knowledge, since ancient times, animal worship, reproductive worship, ancestor worship and traditional ethics and morality have occupied almost all the contents of folk culture. People combine various symbolic objects and create them on paper-cut, posted in every corner of the room, pray for happiness and well-being, children continue, or husband and wife harmony, exorcism disaster. In the Qing Dynasty, "Yanjing Sui Shi Ji", which recorded the old folk custom of Beijing mentioned: "It is used by people and households, but rarely used by large families. "papercut is apparently popular in people's lives, has become a popular, auspicious and festive symbol of folk culture.

\section{THE CREATIVE TECHNIQUE OF PAPER- \\ CUT ART}

\section{A. Exaggeration and distortion}

The traditional paper-cut art is highly subjective, and often uses exaggeration and distortion to express the main image in the process of depiction. As a prominent theme, it does not consider the objective scale of things, nor does it pay attention to the real color of things, more use of high-purity red, blue or black, very few use color matching, focus on the performance of the ideal reality, emphasize the moral and emotional appeal of the function.

\section{B. Abstract characteristic of paper-cut art}

Paper-cut art has a high degree of generality and selectivity, this characteristic does not refer to the paper-cut artist when cutting or not, but refers to their knowledge and choice of the object. The content of Folk paper-cut is almost equal to the entire spiritual and material life of paper-cut artists, the paper-cut artists' living environment, daily articles, animals and figures that can be touched, myths and legends, strange things, the pursuit of a better life and imagination are all embodied in their paper-cut works.
Because of the limitations of paper size and cutting skills, so much of the content is obviously not meticulously carved out, so the image of the refining and selection of art is particularly necessary. In the process of transforming what they see and hear in real life into artistic images, artists choose representative objects with auspicious meanings to mix and match, eliminate unnecessary "reasonable" parts and focus on the intended subject matter. Such as shear fish does not have to accompany the complex water pattern, only with Lotus leaf, both simple and beautiful to explain the living environment of the fish, but also has a good harvest implication.

This kind of artistic technique of abstraction and generalization is reflected in the paper-cut works in almost all areas of China, although most of the relevant literature holds that the artistic techniques of paper-cut are obviously different in the south and the north, for example, southern paper-cut pursuit of fine realism; northern paper-cut simple and lively. However, this feature is not limited to geographical factors, such as the paper-cut works in high density, Shandong Province, where there are often large areas of lines as fine as hair, such as water ripples, surface lines of huge stones, decorative lines inside words, etc., even often the entire animal contour completely by the fine stripes filled, such as chicken feathers line, fish body scales line, etc. , very test the skills of artists. This is clearly a way for the local florist to show off his skills, and does not conflict with the highly refined nature of his artistic image. The southern unearthed some Fan paper-cut works, in addition to the surrounding and a small number of decorative patterns, white part of more than a third of the fan, very simple and generous.

Therefore, we cannot completely use the unrefined and fine to distinguish the north-south paper-cut techniques, and ignore the paper-cut works of the common features of extraction and generalization.

\section{THE ARTISTIC THEME OF PAPER-CUTTING}

\section{A. Exorcism and blessing}

Fu Xi, Nüwa, Yellow Emperor, Queen Mother of the West and others are the main figures in ancient China who changed from totem worship to ancestor worship, according to the ancient people's material and spiritual needs evolved into the god of agriculture, medicine, fertility God, etc. , used to pray for a healthy life, descendants continue, exorcising evil spirits. Among them, the Chignon Doll, as the unique artistic theme of the paper-cutting Image of the ancestor God, has gradually become the folk culture of the God of protection and reproduction, is a very comprehensive performance of this point. Children in the family are sick or crying at night, and sick dolls are pasted at the head of the bed. They are burned with paper and 
knocked on bowls to pray for their stability and recovery. When Tourists Return Home, they burn the soul-summoning dolls to soothe the souls of those who are frightened during the journey, this is described in the southern dynasty poem "paper-cut Evocative My Soul" ; continuous rain, worried that the crops cannot shine on the sun, cut out Sweep Day Lady stick at the door, tell the god quickly sweep away dark clouds, sunny days without rain, then cut out call cloud Lady pray for rain; The couple Bridal Chamber dolls, blessing the prosperity of their children and grandchildren, living in harmony. Chignon Doll and a variety of animal totems, reproductive symbols, auspicious flowers and fruits collocation combination, forming a rich symbolic language, Create whatever protectors you fear, whatever you need. Intuitive expression of the lack of knowledge of the natural sciences in ancient times, people in the state of spiritual self-sufficiency.

\section{B. The etiquette education function}

Due to the strong attachment between paper-cut and daily articles, etiquette education is often posted on the walls and surfaces of articles in homes, and the paper materials are cheap, easy to get, the tools needed are simple and convenient, the effect is immediate, the adaptation is wide, the technique is difficult and easy, and the artists are numerous. With the continuous development of society and culture, various feudal moral thoughts and the imperial examination system took shape and became mature, the paper-cut enlightenment function also appeared. The content of paper-cut is no longer merely to use a single or combination of images to express symbols, nor is it limited to the beauty of life, but to begin to express people's outlook on life, values and spiritual guidance, to tell about feudal morality and etiquette, and to spread the unity of Heaven and man, integration of Buddhism and Taoism and other feudal enlightenment ideas.

The art of paper-cut began to be compatible with the traditional culture and had an impact on the moral spirit and behavior of people at that time. In addition to the conservative nature of farming culture and the characteristics of a continuous line, traditional papercut patterns, like the feudal social system with longterm stability and inheritance, has gradually become one of the typical artistic characteristics of China's traditional culture.

\section{The expectation of having more offspring}

The prosperity of the descendants is the eternal pursuit of life in the farming society. In ancient times, the birth of children is the core purpose of marriage, only continuous birth of the labor force to ensure the prosperity and continuity of the family, so the hope of having more offspring has become an important theme in the paper-cut art. Whether they are pomegranates, cantaloupes, Pumpkins, fertile mice, frogs, Lotus flowers, yin and Yang symbols symbolizing the genitals of men and women, they frequently appear in paper-cut works, a wealth of paper-cut stories and bridal chamber "Happy Flowers" , such as the birth of children in the Lotus, fish playing with the Lotus, fish drilling lotus basin, snake and rabbit, mouse married daughter, mouse bride-snatching, etc. , express the pure reproductive desire and the happy expectation of the full house of the children and the happy life explicitly or implicitly.

\section{THE FORMAL RULES OF PAPER-CUT CREATION}

The formal rules of paper-cut art, like all traditional art forms, are homophonic, Pun, image symbol, etc. These rules and formal features are spread all over China through various media, has Long been an established part of the national culture. Unlike other forms of art, paper-cutting, a folk culture, has a strong language function because of its wide popularity, wide application and close relationship with daily life: When we see a paper-cut work, regardless of one's age, environment and upbringing, the theme and message of the work can be understood almost immediately. For example, the image of the Law of Symbols in the pomegranate, whether in the south or the north, whether in literati paintings, court utensils or Folk Art, pomegranate because of its many seeds and means many children and many blessings ,the paper-cut works put the image of Young Women Together with the pomegranate with its mouth facing down. By means of exaggeration and distortion, the pomegranate is magnified to ten times its normal size and placed directly under the image of women For example, the Gourd in the homophonic method, the Gourd homophonic blessing and wealth, meaning family wealth, but also because of its many seeds and has the meaning of descendants, in the gourd-shaped picture depicting flowers and leaves and Pun "Yin" and the rich hang money pattern, emphasizing its affluence and auspiciousness; the crab has a shell, which in Chinese also passes "a" , signifying "a" in the imperial examination, and the crab is placed with the peony flower, signifying the life of wealth after the success of the imperial examination, is a very strong desire for a better life. These images also have the above-mentioned "good is beautiful, beautiful is good" aesthetic characteristics, practicality and artistry are highly unified, reflecting its conservative agricultural culture by the impact of thought, while, it is also the concentrated expression of the artistry of Social Life in the paper-cut art.

\section{CONCLUSION}

At present, the study of design aesthetics and methodology at home and abroad is different from the 
traditional framework, and no longer obsesses over the relationship between function and form, but tends to use the relevance design thinking to solve the multidisciplinary cross-disciplinary practical research, the combination of technology and contemporary art, social conditions under the influence of user needs and experience process. With the continuous progress of China's economy and culture, with the joint efforts of folk artists, scholars, relevant policies and the development of tourism, traditional art has gradually got out of the struggle for survival, participate in the development of modern design aesthetics. The papercut art comes from and develops in the folk, for thousands of years bearing people's awe of life and beautiful pursuit, providing people with the most simple aesthetic enjoyment and spiritual sustenance, as a traditional technology of beauty, its exuberant vitality will certainly continue to bloom in modern times.

\section{References}

[1] Zhang Daoyi, the swallow tail cuts the spring [M]. Hubei Fine Arts Press, 2003.

[2] Fuchadunchong, yenching records [M]. Beijing Ancient Books Press, 1961.

[3] JinZhilin,chignon doll and the primitive concept of human community[M].Guangxi Normal University Press, 2001.

[4] Feng Zhijie, the folk custom construction in the Ming Dynasty custom painting - Take Shangyuan Dengcai Tu as the Center [J]. National Art, 2019(05)

[5] Hao Ting, Zhang Jinsu, Kai Chen. Applied Research of Horinger County paper-cut art in packaging design[J]. Packaging engineering, 2014, 3504

[6] Li Zhichun, Zhang Lude. The design of the cultural derivative products of Baotou paper-cut [J]. Packaging engineering, 2018, 3922 